\title{
Interviewers' Gender and Interview Topic in Oral Exams
}

\author{
Javad Gholami \\ Department of English, Faculty of Humanities, Urmia University, Iran \\ Karim Sadeghi \\ Department of English, Faculty of Humanities, Urmia University, Iran \\ Sanaz Nozad \\ Department of English, Faculty of Humanities, Urmia University, Iran \\ Email: s.nozad@gmail.com
}

\begin{abstract}
Nowadays, language schools tend to include more of oral exams as part of their course completion assessment instruments in addition to traditional written exams. The major purpose of this study was accordingly to investigate the relationship between interviewers' gender, interview topic and oral performance. Thirty female upper-intermediate students were selected. All the participants were interviewed twice, once by a female and once by a male interviewer and each time they were required to talk about two topics, one gender-neutral and another gender-biased. All the performances were scored twice with an inter-rater reliability of +.88 and +.89 for two interviews respectively. A comparative analysis of the interview scores indicated that students achieved higher scores when interviewed by a female interviewer. With respect to interview topic, students performed better on gender-neutral topic.
\end{abstract}

Index Terms-interviewer's gender, interview topic, gender-neutral, gender-biased, oral performance

\section{INTRODUCTION}

There are a lot of variables which may affect language learners' performance in oral tests. The age, status, personality-type, acquaintance-relationship, topic area, and the gender of the participants are among these variables (Porter, 1991a). In this regard, various studies have been conducted to show the influence of the participants' characteristics on their performance in tests of spoken language.

One of the variables that may have a relationship with test takers' performance in oral exams is the gender of the person with whom they interact (O'Sullivan, 2000). Interviewers usually differ from each other based on their test behavior like, how much support they give to interviewees, how friendly they behave towards interviewees, and to what extent they act their role following relevant instructions (O'Loughlin, 2002). As male and female conversational styles are completely different, many researchers (e.g., Maltz \& Borker, 1982; Tannen, 1990; Coates, 1993; Thwaite, 1993) believe that gender differences in communicative style can be one reason to explain the differences between interviewers (O'Loughlin, 2002). Male and female interviewer's different styles and their different behavior towards male and female interviewees can be one possibility of gender effect in oral interviews and may affect the results of the interview by helping or preventing the candidates from performing well (Sunderland, 1995). Hence, the interviewer's gender can affect the students' performance positively or negatively (O'Loughin, 2002).

Another variable which may affect interviewers' performance is the topic about which they should talk in oral exams (Lumley \& O'Sullivan, 2005). Sunderland (1995) believes that "Topic", "Task" and "Tester" are among the variables that may favor male or female interviewees. There is a possibility for a particular topic to be more familiar to males or females, so it makes the interviewees perform better and in a more comfortable way in oral exams (Lumley \& O'Sullivan, 2005).

In his exploratory study on a small group of male Arab students, Lock (1984) found that when the students were interviewed twice, once by a man and once by a woman, they got higher scores with the male interviewer. Porter (1991a) followed this study while focusing on the gender and personality of the participants and their degree of acquaintanceship. Based on the results of this study, the only variable that had a significant effect on the students' performance was the 'gender' variable, and participants obtained higher scores when interviewed by male interviewers.

Porter (1991b) examined the effect of interviewers' gender and participants' perceived status of the interviewers on a group of Algerian participants' (12 men and 4 women) oral performance. The researcher controlled the statues of the interviewers and they were introduced to each participant differently, in terms of the manner, physical proximity, and the introducer's tone of voice, i.e. their dress, the formality of the introduction and the introducer's respect while introduction marked them as high/ low status. The results showed that students got higher scores when interviewed by a man and by a person who had not been marked for higher status. In a different study, Porter and Shen (1991) focused 
on the effect of gender; status and interaction style (male/female) and found no significant relationship between these factors and the students' performance. However, based on the findings of this study, students got higher scores when interviewed by a woman.

O'Sullivan (2000) studied the effect of the interviewers' gender on students' oral performance. The results of his study supported the findings of Porter and Shen (1991) that interviewers' gender affected the interviewees' performance. The results also showed that participants had produced language more accurately when interviewed by a woman. Lumley and O'Sullivan (2005) examined the effect of the test-takers' gender, the gender of the audience and topic on test-takers' performance and claimed that the task topic might have an effect on test-takers' performance especially if the gender of the audience varies. They hypothesized that males might outperform females if the task topic is male-oriented especially when the audience is male while with female audience there can be slight advantage to males, i.e. male-oriented topic along with male audience makes the topic harder for females.

As English education in Iran tend to improve Iranian English learners' communicative ability, testing methods has been changed in recent years and most of the language institutes try to assess students' language proficiency using oral exams, however one of the problems which most of the Iranian English learners are facing with during oral exams is the presence of some factors like audiences and tasks which may act as barriers.

Thus, this study takes an aim to investigate the relationship between interviewers' gender and interview topic with students' oral performance. The correlation between interviewers' gender and interview topic with students' oral performance was calculated respectively. More specifically, the study reported in this article addressed the following questions:

1. Is there any relationship between interviewers' gender and EFL learners' performance in oral exams?

2. Is there any relationship between the nature of the topic and EFL learners' performance in oral exams?

\section{METHOD}

\section{A. Participants}

Thirty Iranian EFL learners studying at Jahad Daneshgahi Language Institute in Urmia, Iran, participated in this study. All the participants were female with upper-intermediate proficiency level. Their language proficiency was rated as upper-intermediate based on the institute's in-house placement test and final exam results. The participants were preferred to be female because of the women's socio-cultural status in Iran which may have relationship with their performance when they interact with the opposite sex. The mean age of the participants was 20. Two interviewers (one man and one woman) also participated in this study. They were experienced English teachers who had interviewed students for many years at this institute.

\section{B. Instruments}

Two series of interviews (one by a female and one by a male) were conducted in this study to ascertain the relationship between interviewers' gender and test-takers' oral performance.

\section{Procedure}

This study was conducted at Jahad Daneshgahi Language Institute in Urmia, Iran. All students with intermediate level of proficiency who study at this institute are required to take part in a two-phase final exam (a written test and an oral interview) if they want to continue their studies in upper levels. In fact this exam can be considered a placement test which determines whether students are eligible to enroll at upper-intermediate level classes or not. In order to have participants with the same proficiency level, the researchers chose 30 students who were successful in passing the written exam, so all the participants were considered upper- intermediate.

All these 30 students were asked to take part in oral interview as their part of final exam assessment. All the students were interviewed twice, once by a female interviewer and once by a male interviewer and each time they were asked to talk about two topics (one gender-neutral and one gender-biased). The topics were chosen based on a consensus by 10 experienced teachers. 18 gender-neutral and 18 gender-biased topics which had been used in IELTS interviews in the past were chosen. At the same time 10 experienced teachers who had taught at this institute for several years were selected and asked to choose the topics that were the most appropriate ones for the interview regarding participants' proficiency level.

The topics which were chosen by most of the teachers were selected as the interview topics. In order to for the results to be comparable, it was necessary for the interviews to be similar, but not in a way that the second interview would be considered as a mere replication of the first one. As a result, two similar, but not identical interviews were conducted. In other words, both interviews followed the same structures with the same general topic area, but with different specific content. As participants were required to take part in two interviews and as talking about the same topics twice may have provided the possibility for the better performance in the second interview, two other topics which were similar to the first ones and which required the same amount of knowledge and proficiency as the first ones were chosen. All in all, in this study 4 topics were used in total (two gender-neutral and two gender-biased).

Considering Iranian culture, in which it is embarrassing for a woman to speak with an opposite sex and taking into account the additional embarrassment which may be caused by the topics that are embarrassing by nature, in this study 
gender-neutral topic refers to the topics which are not embarrassing to both genders, while gender-biased topics are considered as the topics that are embarrassing and make female students feel uncomfortable, especially when talking with a male interviewer.

All interviews were conducted under similar conditions in a pair of adjacent interview rooms. The first interview was conducted by a female interviewer and students were required to talk about two topics, i.e. first, gender-neutral one, namely: How do you spend your weekends? secondly, gender-biased: What is your idea about engagement period? All the performances were scored at the time of the interview by the interviewer discretely, i.e. she awarded scores using a four scale criteria (vocabulary, grammar, fluency and pronunciation, see appendix).

Each test-taker was awarded two scores, one for gender-neutral topic and one for gender-biased topic and the mean score of two topics was obtained. Meanwhile, all the interviews were audio taped for further reference. In order to establish inter-rater reliability, the performances of five students were scored once more by one of the researchers to be compared with the score given by the interviewer himself/herself. The value of correlation coefficient $(\alpha=+0.88)$ showed that there was a high degree of agreement between the scores given by two raters, and it was concluded that the scores awarded by the interviewer were reliable and the rest of the performances were scored only by the female interviewer.

In order to see whether interviewers' gender has any relationship with students' performance, a parallel interview (with similar topics as the first interview, i.e. first, gender-neutral: How do you spend your free time? Second, genderbiased: What is your idea about marriage?) was conducted by a male interviewer. All the interviews were audio taped and all the performances were scored in the same way as the first interview. In order to establish inter-rater reliability, like the first interview, the performances of 5 students were scored by one of the researchers. As the coefficient of correlation was +0.89 , it was concluded that the scores awarded by the interviewer were reliable and the rest of the performances were scored only by the male interviewer.

\section{RESULTS}

\section{A. Descriptive Statistics for the Oral Test Grades}

This subsection reports quantitative findings for students' oral test grades considering interviewers' gender and interview topic.

TABLE 1.

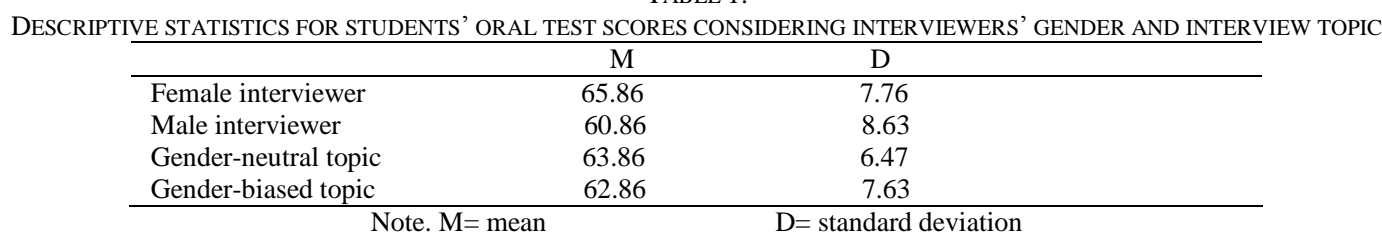

\section{B. Interviewers' Gender and Students' Oral Performance}

In order to see if there is a relationship between interviewers' gender and students' oral performance, correlation between two variables was calculated and since one of the variables, i.e. interviewers' gender was dichotomous and the other, i.e. oral performance was continuous, Pearson correlation was used for this purpose (Pallant, 2007). Tables 2 indicate the corresponding coefficients.

TABLE2.

PEARSON CORRELATION FOR INTERVIEWERS' GENDER AND STUDENTS' ORAL TEST SCORES

\begin{tabular}{lll}
\multicolumn{4}{c}{ PEARSON CORRELATION FOR INTERVIEWERS' GENDER AND STUDENTS' ORAL TEST SCORES } \\
\hline Pearsolation & $\mathrm{r}$ & $\mathrm{p}$ \\
\hline Interviewers' gender and oral test grades & .44 & .01 \\
\hline
\end{tabular}

As it is shown in table 2, the Pearson correlation between interviewers' gender and students' oral test scores was statistically significant $(\mathrm{r}-.44, \mathrm{p}=.01)$, and as it was shown in table 1 , students obtained higher scores with the female interviewer.

\section{Interview Topic and Students' Oral Performance}

To investigate the relationship between the nature of interview topic and students' oral test grades, another Pearson correlation was run between interview topic and students' oral test grades.

TABLE 3.

PEARSON CORRELATION FOR INTERVIEW TOPIC AND STUDENTS' ORAL TEST GRADES

\begin{tabular}{lcc}
\hline Pearson Correlation & $\mathrm{r}$ & $\mathrm{p}$ \\
\hline Interview topic and oral test grades & .96 & .00 \\
\hline
\end{tabular}


Table 3 indicates that the correlation between interview topic and students' oral test grades was statistically significant $(\mathrm{r}=.96, \mathrm{p}=.00)$, and as it was shown in table 1 , students obtained higher scores on gender neutral topic.

\section{DISCUSSION}

\section{A. Interviewers' Gender and Oral Performance}

Investigating the relationship between interviewers' gender and students' oral performance showed that students performed better when interviewed by a female interviewer. As it was mentioned earlier, considering Iranian culture, it was expected to find a relationship between interviewers' gender and students' oral performance, that students were expected to perform better with the female interviewer.

There have been a number of studies which have investigated the possibility of a gender effect in oral interviews. Like the present study, most of these studies showed that there was a relationship between gender and test scores, but the findings differed from one study to another one. In other words, some studies reported that students obtained higher scores when interviewed by a male interviewer (Locke, 1984; Porter, 1991a; 1991b) and some others found that students got higher scores when interviewed by a female interviewer (Porter and Shen, 1991; O'Sullivan, 2000). Buckigham (1997) is among the researchers who claimed that women might feel more comfortable talking to a female interviewer; she found the same-sex effect on Japanese EFL learners' oral performance.

On the other hand, the findings of the present study contradict with the outcomes of the study which was conducted by O'Loughlin (2002), according to which there was no gender effect in interviews. He tried to find not only the impact of interviewers' gender, but also the impact of the gender of test takers and raters on test scores in IELTS interviews, and found that gender did not have a significant effect on the IELTS oral interview.

To explain the contradiction between the findings of his study, and other recent studies, we can refer to O'Loughlin (2002) who stated that the inconsistency of the findings might result from social identities of the test-takers and interviewers, i.e. their age, gender, and ethnicity as well as the characteristics of the testing context, like the country where it is administered, and the purpose of the test.

\section{B. Interview Topic and Oral Performance}

Another focus of this study was on the relationship between interview topic and students' oral performance. As it was expected, students obtained higher scores when they were required to talk about gender-neutral topic. There are many topics which are embarrassing for Iranian women to talk about; engagement and marriage are two examples of these embarrassing topics which are difficult for Iranian women to talk about and they prefer not to talk about such topics.

A study conducted by Lumley and O'Sullivan (2005) investigated the impact of topic on students' performance, but gender-biased topic in this study refers to topic which is more interesting and familiar to males, like horse racing which is male-oriented and housing and places to visit which are gender-neutral. They reported that males might outperform females if the task topic is male-oriented especially when the audience is male while with female audience there can be slight advantage to males, i.e. male-oriented topic along with male audience make the topic harder for females.

\section{CONCLUSION}

Interviewer' gender and interview topic are among the variables which have been investigated by many researchers and it was found as a variable which may have a positive or a negative relationship with students' oral performance. Based on the findings of the present study, interviewers' gender has a relationship with students' oral performance and students performed better with female interviewer. Considering interview topic it was found that students performed better on gender-neutral topic.

\section{APPENDIX. INTERVIEW QUESTIONS.}

Name:

level:

\section{Topic 1}

How do you spend your weekends?

Do you spend your weekends in different way from weekdays? How?

Where do you go?

Who do you spend your weekends with? Why do you prefer this person?

Fluency and coherence: 1-25

Vocabulary: 1-25

Grammatical range and accuracy: 1-25 
Pronunciation: $1-25$

Total score: 1-10

\section{Topic 2}

What is your idea about engagement period?

Do you like to get engaged before getting married?

Do you think that being engaged affects marriage? How?

Is being engaged for a long time good? Why?

How long do you like to stay engaged?

What are the advantages and disadvantages of engagement period?

Fluency and coherence:

$1-25$

Vocabulary: 1-25

Grammatical range and accuracy: 1-25

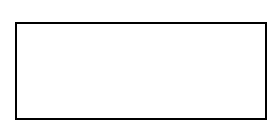

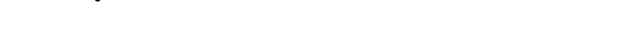
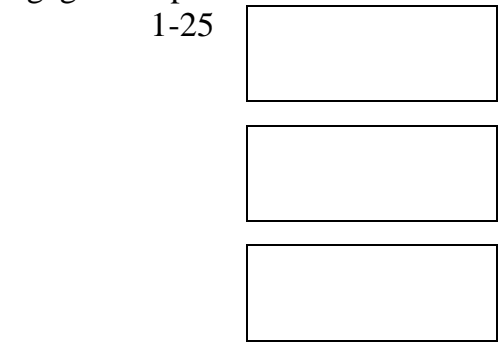

Pronunciation: $1-25$

Total score: $1-100$

Name:

\section{Topic 1}

How do you spend your free time?

What is the most enjoyable activity you do in your free time? Why?

Do you like to spend your free time alone? Why?

Who do you like to spend your free time with? Why do you prefer this person?

Fluency and coherence:

level:

Vocabulary: 1-25

Vocabulary: 1-25

Grammatical range and accuracy: 1-25

Pronunciation: 1-25

Total score: $1-100$

$1-25$

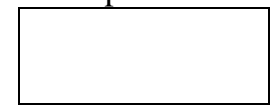

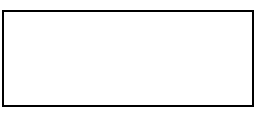
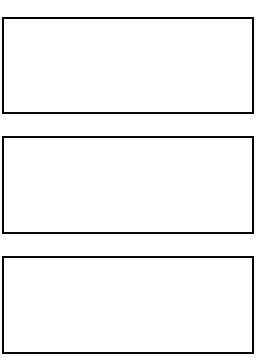

Topic 2

What is your idea about marriage?

Do you like to marry or remain single?

Do you like to marry young?

When is the right time for marriage?

Do you like to have right to propose to your favorite boy for marriage?

Talk about your expectations of marriage.

What are the characteristics of your ideal husband? 
What are the advantages and disadvantages of a successful marriage?

Fluency and coherence: 1-25

Vocabulary: 1-25

Grammatical range and accuracy: 1-25

Pronunciation: 1-25

Total score: $1-100$
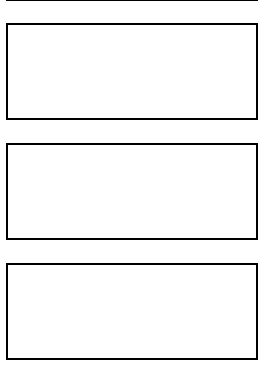

\section{REFERENCES}

[1] Buckingham, A. (1997). Oral language testing: Do the age, status and gender of the interlocutor make a difference? Unpublished master's thesis, University of Reading, Berkshire, England.

[2] Coats, J. (1993). Women, men and language (2th ed.). Harlow, England: Longman.

[3] Lock, C. (1984). The influence of the interviewer on student performance in tests of foreign language oral/aural skills. Unpublished master's theses, University of Reading, Berkshire, England.

[4] Lumley, T., \& O'Sullivan, B. (2005). The effect of test-taker gender, audience and topic on task performance in tape-mediated assessment of speaking. Sage, 22(4), 415-437.

[5] Maltz, D., \& Borker, R. (1982). A cultural approach to male-female miscommunication. In J. Gumperz (Ed.), language and social identity (pp. 196-216). Cambridge: Cambridge University Press.

[6] O'Loughlin, K. (2002). The impact of gender in oral proficiency testing. Language Testing, 19, 169-192.

[7] O'Sullivan, B. (2000). Exploring gender and oral proficiency interview performance. Journal of System, 28, 373-386.

[8] Pallant, J. (2007). SPSS: Survival manual (3th ed.). Berkshire, England: Open University Press.

[9] Porter, D. (1991a). Affective factors in language testing. In C. J. Alderson \& B. North (Eds.), Language testing in the 1990s (pp. 32-40). London: Modern English Publications.

[10] Porter, D. (1991b). Affective factors in the assessment of oral interaction: Gender and status. In S. Arniva (Ed.), Current development in language testing (pp. 92-102). Singapore: SEAMEO Regional Language Center.

[11] Porter, D., \& Shen. H. (1991). Sex, status, and style in the interview. Dolphin, 21, 117-128.

[12] Sunderland, J. (1995). Gender and language testing. Language Testing Update, 17, 24-35.

[13] Tannen, D. (1990). You just don't understand: Women and men in conversation. New York: William Morrow.

[14] Thwaite, A. (1993). Gender differences in spoken interaction in same dyadic conversations in Australian English. In J. Winter \& G. Wigglesworth (Eds.), Language and gender in the Australian context. Australians Review of Applied Linguistics Series S No. $10,149-79$.

Javad Gholami is an Assistant Professor in TEFL from Urmia University. He has been working as an EFL/ESP practitioner and teacher trainer for more than 10 years. His research publications have been on integrating focus on form and communicative language teaching, intralingual translation and learner autonomy in ELT.

Karim Sadeghi has a PhD in TEFL/TESOL (Language Testing) from the University of East Anglia in Norwith, UK. Since his return to Iran in September 2003, he has been lecturing and researching in Urmia University, Iran. His main research interest include: language testing, alternative assessment, reading comprehension and error analysis. He was selected as the best researcher of Urmia University in 2007, and he served as the Deputy Head of the English Language Department from April 2007 to January 2010 when he was elected as the Head of the English Language Department. He has also been working as an editor for the Chinese EFL Journal since January 08 .

Sanaz Nozad is currently an MA student in Teaching English as a Foreign Language (TEFL) in Urmia University. 